\title{
Structure Types and Discourse Function of N+N Nominal Sentence in Mandarin Chinese
}

\begin{abstract}
ZHANG Li-juan
Wuhan University, Wuhan, Hubei, P. R. China

$\mathrm{N}+\mathrm{N}$ nominal sentence is an important structure type of nominal sentences in Mandarin Chinese. Attributive-center, combination, apposition and subject-predicate are its main structure types. In main literary genres, the distribution of $\mathrm{N}+\mathrm{N}$ nominal sentence shows a certain trend of dominant hierarchy: poem > drama > novel > prose. No matter what kind of literary genres, attributive-center structure is the type with maximum quantity, while appositive structure is the type with minimum quantity. Statistical result indicates that most of $\mathrm{N}+\mathrm{N}$ nominal sentence is nominal and its use is limited by genres. Function of $\mathrm{N}+\mathrm{N}$ nominal sentence is textual. When it comes to discourse, it can be used as theme, rheme and dual identity of theme and rheme based on the theory of Theme-Rheme (T-R) structure pattern. It does not only construct the information structure to deliver textual information, but also its a vital means of discourse cohesion and coherence.
\end{abstract}

Keywords: $\mathrm{N}+\mathrm{N}$ nominal sentence, discourse, information structure

\section{Introduction}

Nominal sentence in mandarin Chinese refers to a sentence in which the noun is the core component. It is complicated to define "sentence" in mandarin Chinese. In order to define nominal sentence, we should define "sentence" firstly. "Structurally, a sentence usually contains a subject and a predicate, but it is not absolute. Followed by a certain intonation, one phrase or word can also be a sentence” (Lv, 1979, p. 28). Xing (1996, pp. 13-15) adopted Lv's concept of "small sentence", and asserted that "small sentence is the smallest grammatical unit with declarative and independent feature". He also defined its extension, "firstly, small sentence refers to simple sentence, secondly, small sentence refers to clause which has the similar structure with simple sentence". Chao (2011, pp. 83, 106) argued that "sentences may be classified, from the point of view of structure, into full and minor sentences. A full sentence consists of two parts, a subject and a predicate, and is the commonest type in connected discourse. It is in this sense the favorite sentence type in Chinese, as it is in many other languages. A minor sentence is not in the subject-predicate form. "It occurs more frequently in two-way conversation and in speech interposed or accompanied by action than it does in connected discourse." "Minor sentences are more primary than full sentences and it does help the understanding of sentence structure to analyze a full sentence as made up of minor sentences." "Thus we have arrived at the surprising, and yet obvious, conclusion that a full sentence is a complex sentence consisting of two minor ones.” Upon his viewpoint, Shen (2012) explained

ZHANG Li-juan, Ph.D. candidate, Wuhan University, Wuhan, Hubei, P. R. China. 
"that is to say, full sentence in mandarin Chinese is the simple sentence with complete subject and predicate. If the sentence is separated by a pause or stop particle, then it becomes a complex sentence. The subject is not a structure but a clause, and the predicate is another clause” (p. 404) From the previous perspective, we can find out that the phrase with intonation in mandarin Chinese is also sentence or clause. They have the same function with subject-predicate sentence. This kind of sentence or clause is important language material to construct mandarin Chinese discourse, especially in oral Chinese.

Example (1)

船上这几位, 有在法国留学的, 有在英国、德国、比国等读书, 到巴黎去增长夜生活经验, 因此也坐法国船 的。(钱钟书, 1980, p. 2)

According to the definition of “sentence (clause)”, N+N nominal phrase “船上这几位” with comma (,), can be regarded as $\mathrm{N}+\mathrm{N}$ nominal sentence in mandarin Chinese although it doesn't have typically subject and predicate. Based on its discourse function and our discourse research perspective, it is sentence (clause) instead of phrases. In Example (1), N+N nominal sentence “船上这几位,” is the starting point of the paragraph, and it provides a topic to both sides of communication. The speaker uses this topic to attract and deliver information to the listener, while the listener uses this topic to accept and explore communicative intention from speaker. So in this paragraph, “船上这几位,” provides a platform to both sides of communication. In the perspective of communicative function, it is sentential and textual. In the communicative system, sentence or clause is the basic unit, so it is a clause or sentence rather than a phrase. If the discourse consists in serial such units, one is called clause. If not, such unit is called sentence. Whatever, this unit can't be called phrase.

According to the amount of syntax component which sentences contain, nominal sentence can be divided into two main types. One only contains a single noun or nominal composition (the numeral component, nominal pronoun composition, the structure of "de"), such as single nominal sentence. The other contains other elements except for core nominal elements, such as $\mathrm{N}+\mathrm{N}, \mathrm{V}+\mathrm{N}$ and $\mathrm{A}+\mathrm{N}$ nominal sentence.

This paper talks about $\mathrm{N}+\mathrm{N}$ nominal sentence which is an important type of nominal sentence as the research target, using the statistical approach of authentic material to summarize its distribution rules in discourse or text, study its discourse construction function in the Theme-Rheme (T-R) structure pattern.

\section{Main Structure Types of N+N Nominal Sentence}

There are many structure types of $\mathrm{N}+\mathrm{N}$ nominal sentence. Classifying them and describing the subclass can be helpful to understand the characteristic and function of $\mathrm{N}+\mathrm{N}$ nominal sentence. And it is also helpful to build up the nominal sentence structure system and discourse analysis system.

In order to investigate the main structure types of $\mathrm{N}+\mathrm{N}$ nominal sentence, we have collected authentic material from the main literary genre-poem, prose, fiction and drama. From this material, we found that attributive-center, combination, apposition and subject-predicate are the four main structure types of $\mathrm{N}+\mathrm{N}$ nominal sentence.

1. Attributive-center structure of $\mathrm{N}+\mathrm{N}$ nominal sentence

In attributive-center structure of $\mathrm{N}+\mathrm{N}$ nominal sentence, the relationship of two nouns is a modifier and a modified element. In mandarin Chinese, the first noun is attributive element and the second noun is central 
word in the sentence.

Example (2)

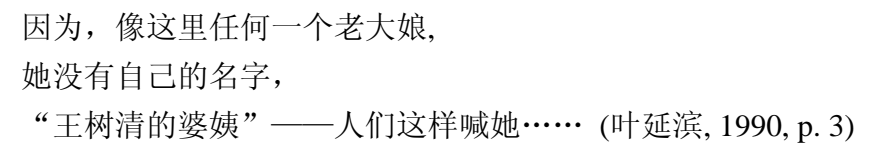

In Example (2), the N+N nominal sentence “王树清的婆姨” is constituted by two nouns “王树清” and “婆姨”. This two nouns have different properties, the first noun “王树清” is a modifier and the second noun “婆姨” is a modified element. The first noun modifies the second noun, and the second one is center of the structure. In mandarin Chinese, Attributive-center structure of $\mathrm{N}+\mathrm{N}$ nominal sentence is the right core structure.

2. Combination structure of $\mathrm{N}+\mathrm{N}$ nominal sentence

In combination structure of $\mathrm{N}+\mathrm{N}$ nominal sentence, the two nouns have equal status. From the view of grammar, the two nouns are self-governed, and the combination of their joint is just based on vocabulary. That is to say, the two nouns can serve as syntactical elements independent.

Example (3)

第一三一号《双松湖亭图》, 一三二号《深山访隐图》, 一三三号《秋水始生图》, 一五六号《柴门归客图》, 皆明人大幅立轴, 气息深稳, 局势宏阔。(苏雪林, 2013, p. 228)

In Example (3), the nominal sentences “第一三一号《双松湖亭图》, ” “一三二号《深山访隐图》, ” “一 三三号《秋水始生图》, ” “一五六号《柴门归客图》, ” are independent syntactical elements. While they are aggregated into a whole, the lexical meaning not their grammatical characteristic has been changed. That is to say, when the four sentences form an organic whole, it only adds the lexical meaning while the property of the grammatical character is still nominal.

3. Apposition structure of $\mathrm{N}+\mathrm{N}$ nominal sentence

In apposition structure of $\mathrm{N}+\mathrm{N}$ nominal sentence, the two nouns refer to the same thing. The two parts $\mathrm{N} 1$ and $\mathrm{N} 2$ are identical, they have the same grammatical function. The two parts share the same grammatical and lexical meaning. And in its internal, the two parts explain each other.

Example (4)

刘大娘：俊孩子, 关伯伯这位大夫, 只能救人家伤风咳嗽, 怎么救得了杀头？娘在说话, 别扰我吧。（田汉, 2000, p. 6)

In Example (4), N1 “关伯伯” and N2 “这位大夫” refer to the same person, they are used as the subject of the whole structure. In fact, either “关伯伯” or “这位大夫” can take the position of subject by itself. That is to say, the grammatical function of the two parts are the same, so as the lexical meaning.

4. Subject-predicate structure of $\mathrm{N}+\mathrm{N}$ nominal sentence

In subject-predicate structure of $\mathrm{N}+\mathrm{N}$ nominal sentence, the relationship between the two nouns is subject-predicate. That is to say, N2 asserts N1. In this type, N2 is used as verbal grammatical functions. This is different from many languages, such as English. In English, predicate part must be verbal. 


\section{Example (5)}

他年龄刚二十八岁, 新有过一次不幸的恋爱经验, 可是他看破了教育, 看破了政治, 看破了一切, 哼！（钱 钟书《围城》）(钱钟书, 1980, p. 124)

In Example (5), N2 “刚二十八岁” asserts N1 “他年龄”, and it is used as predicate of this sentence. This kind of nominal sentence is an important sentence pattern in mandarin Chinese, it is called "nominal predicate sentence".

Attributive-center, combination, apposition and subject-predicate are the four main structure types of $\mathrm{N}+\mathrm{N}$ nominal sentence. In these four types, attributive-center, combination and apposition structure are endocentric construction. For these types, function of the structure is equivalent to one of its constituents. As to $\mathrm{N}+\mathrm{N}$ nominal sentence, these three types are nominal. Comparing with the three, subject-predicate is exocentric construction which none of the words is functionally equivalent to the a whole. That is to say, this type is nonnominal. Nominal and nonnominal characteristic of $\mathrm{N}+\mathrm{N}$ nominal sentence will have influence on its discourse function.

\section{Discourse Distribution of N+N Nominal Sentence}

Novel, poem, prose, and drama are the main literary genres in mandarin Chinese, and they provide the primary distribution space for $\mathrm{N}+\mathrm{N}$ nominal sentence. In order to observe the frequency, it is a feasible way to extract $\mathrm{N}+\mathrm{N}$ nominal sentence from the four genres respectively.

Table 1

Distribution ratio of $N+N$ Nominal Sentence in Main Literary Genres

\begin{tabular}{lllll}
\hline Literary genres & Novel & Poem & Prose & Drama \\
\hline Word count (10000) & 22 & 19.8 & 38 & 30.9 \\
Sentences count & 250 & 314 & 424 & 446 \\
Average & 11.36 & 15.86 & 11.16 & 14.43 \\
\hline
\end{tabular}

Collecting 220,000 words from novel, 198,000 words from poem, 380,000 words from prose and 309,000 words from drama, we received 250,314,424 and $446 \mathrm{~N}+\mathrm{N}$ nominal sentences respectively. The average is 11.36, 15.86, 11.16 and 14.43 sentences per 10000 words. Statistics result indicates that the distribution ratio of $\mathrm{N}+\mathrm{N}$ nominal sentence is different from each other in different literary genres. It shows a certain trend of dominant hierarchy:

poem $>$ drama $>$ novel $>$ prose

Reason for this trend may be rooted in the expression mode of different genres. Generally, poem needs compact sentences to create artistic conception, and $\mathrm{N}+\mathrm{N}$ nominal sentence is short and implicative. Thus it meets the need of poem's expression requirement. Drama and novel need dialogue and background knowledge to motivate the plot development. Recording and describing dialogue and background knowledge need both of nominal and nonnominal sentences. $\mathrm{N}+\mathrm{N}$ nominal sentence can provide most of nominal and some nonnominal sentences, while other types of sentences provide most of nonnominal sentences. That's why $\mathrm{N}+\mathrm{N}$ nominal sentence takes a certain proportion but not as much as in poem. Prose is narrative and concentrates more on expressing the author's viewpoint. It usually needs full structure (subject-predicate structure) sentences, so $\mathrm{N}+\mathrm{N}$ nominal sentence is not so much in this genre. 
In order to research the distribution of $\mathrm{N}+\mathrm{N}$ nominal sentence better in main literary genres, we also take its subclass proportion to consider.

Table 2

The Proportion of $N+N$ Nominal Sentence in Different Literary Genres

\begin{tabular}{|c|c|c|c|c|}
\hline $\begin{array}{l}\text { Structure } \\
\text { Genres }\end{array}$ & $\begin{array}{c}\text { Attributive-center } \\
\text { structure }\end{array}$ & $\begin{array}{c}\text { Combination } \\
\text { structure }\end{array}$ & $\begin{array}{l}\text { Apposition } \\
\text { structure }\end{array}$ & $\begin{array}{c}\text { Subject-predicate } \\
\text { structure }\end{array}$ \\
\hline Novel & $\begin{array}{c}59.2 \% \\
\text { (148 sentences) }\end{array}$ & $\begin{array}{c}17.6 \% \\
\text { (44 sentences) }\end{array}$ & $\begin{array}{c}6.4 \% \\
\text { (16 sentences) }\end{array}$ & $\begin{array}{c}16.8 \% \\
\text { (42 sentences) }\end{array}$ \\
\hline Poem & $\begin{array}{c}62.7 \% \\
\text { (197 sentences) }\end{array}$ & $\begin{array}{c}30.6 \% \\
\text { (96 sentences) }\end{array}$ & $\begin{array}{c}1.6 \% \\
\text { (5 sentences) }\end{array}$ & $\begin{array}{c}5.1 \% \\
\text { (16 sentences) }\end{array}$ \\
\hline Prose & $\begin{array}{c}62.3 \% \\
\text { (264 sentences) }\end{array}$ & $\begin{array}{c}23.1 \% \\
\text { (98 sentences) }\end{array}$ & $\begin{array}{c}4.2 \% \\
\text { (18 sentences) }\end{array}$ & $\begin{array}{c}10.4 \% \\
\text { (44 sentences) }\end{array}$ \\
\hline Drama & $\begin{array}{c}38.1 \% \\
\text { (170 sentences) }\end{array}$ & $\begin{array}{c}21.3 \% \\
\text { (95 sentences) }\end{array}$ & $\begin{array}{c}9.0 \% \\
\text { (40 sentences) }\end{array}$ & $\begin{array}{c}31.6 \% \\
\text { (141 sentences) }\end{array}$ \\
\hline
\end{tabular}

From the statistics result of table 2, it can be summarized as follow.

Firstly, no matter what kind of literary genres, attributive-center structure is the type with maximum quantity, while apposition structure is the type with minimum quantity. That is to say, attributive-center is a typical form and appositive is a non-typical form in $\mathrm{N}+\mathrm{N}$ nominal sentence.

Secondly, the proportion of subject-predicate structure in drama is much bigger than in other literary genres. Subject-predicate structure of nominal sentence, which is also called nominal predicate sentence, is a particular sentence type in mandarin Chinese. It usually emerges in oral language. Dialogue and monologue are the major presentation of drama. And most of the dialogue and monologue are oral language. It may be the reason why so big proportion presents in this genre. It also shows that oral characteristic of the chosen drama.

Thirdly, comparing with other literary genres, combination structure is with high priority in poem. Poem is apt to use concise, compact and imagery words or sentences to express, and combination structure of $\mathrm{N}+\mathrm{N}$ nominal sentence is belief and meaningful. It just coincides with the poem's style characteristics.

From the statistical result and analysis, we can infer that the choice of language form is related to the genre. We believe that genre restricts language producer's (the author or speaker) choice and use of linguistic forms, such as the sentences and lexical structure types.

\section{Discourse Information Function of $\mathbf{N}+\mathbf{N}$ Nominal Sentence}

$\mathrm{N}+\mathrm{N}$ nominal sentence plays a crucial part in discourse information delivery, its function is textual. Theme-Rheme (T-R) structure is an important analytical method to discourse information function. Mathesius, a well-known scholar of Prague school, first proposed to analyze the sentence by this way. He divided the sentences into theme and rheme from the perspective of information delivery. Halliday accepted and developed the theory in his discourse analysis theory system. In T-R structure analytical method, theme, at the beginning of the sentence, is the starting point of information. It is the first component of sentence information structure and generally contains given information. And rheme, the rest of the sentence, often contains new information which is the communication focus. Besides that, Halliday also divided theme into three parts, ideational composition, interpersonal composition and discourse (textual) composition, which corresponds to topical theme, interpersonal theme and textual theme. 
This theory of information structure is also suitable to analyze the discourse information function of $\mathrm{N}+\mathrm{N}$ nominal sentence. The $\mathrm{N}+\mathrm{N}$ nominal sentence distribution indicates that they can be taken as theme, rheme and dual identity of theme-rheme. That's to say, $\mathrm{N}+\mathrm{N}$ nominal sentence can take up the position of starting point, the rest and the dual, its function is used as theme, rheme and dual identity of theme-rheme.

Firstly, $\mathrm{N}+\mathrm{N}$ nominal sentence takes up the position of starting point, and it is used as theme. When $\mathrm{N}+\mathrm{N}$ nominal sentence is used as theme, it is especially apparent in attributive-center, the combination, and most of the appositive structure in $\mathrm{N}+\mathrm{N}$ nominal sentence. This is because $\mathrm{N}+\mathrm{N}$ nominal sentence with these kinds of structures belongs to endocentric structure and the function of whole structure is the same as the headword. That means the whole structure is nominal. Nominal sentence appears at the starting point of the discourse, where is also the starting point of discourse information structure. In this position, the theme usually provides foregrounding information for the whole discourse.

Used as theme, $\mathrm{N}+\mathrm{N}$ nominal sentence can be topical theme. In Halliday's theory, the sentence or clause in its representational function, construes a quantum of human experience: some process. The processes are construed as configuration of components of three types, and the participants in the process is one of these three. (Halliday, 2008, p. 79) The participants are usually acted as an $\mathrm{N}+\mathrm{N}$ structures. Adding intonation, $\mathrm{N}+\mathrm{N}$ structure upgrades to $\mathrm{N}+\mathrm{N}$ nominal sentence. That's to say, used as topical theme is one of the important discourse function of $\mathrm{N}+\mathrm{N}$ nominal sentence. Topical theme is the main component in the information structure. It is the participating ingredient of process. The role of topic in a sentence is textual function, but not a necessarily dominant element of the predicate verb. Its primary function is to establish a basic statement framework for the coming part.

Example (6)

船上这几位，有在法国留学的，有在英国、德国、比国等读书，到巴黎去增长夜生活经验，因此也坐法国船 的。他们天涯相遇, 一见如故, 谈起外患内乱的祖国, 都恨不得立刻就回去为它服务。(钱钟书, 1980, p. 2)

In Example (6), “船上这几位”, the attributive-center of $\mathrm{N}+\mathrm{N}$ nominal sentence, used as the participant of the process, sets up the basically statement framework for the coming part. It is used as topical theme of the paragraph.

$\mathrm{N}+\mathrm{N}$ nominal sentence can also be used as interpersonal theme. Interpersonal theme consists of address, mood composition, tone markers and so on. $\mathrm{N}+\mathrm{N}$ nominal sentence, which is generated by address and punctuation mark, is used as interpersonal theme of the whole paragraph or discourse. Function of address is for attracting the listeners, and its typical (but don't have to) language form is the name of someone. It can almost appear at any position of the discourse, and is especially true in conversational discourse. If it appears in the starting point but not the topical theme, it is the interpersonal theme. That is to say, if the $\mathrm{N}+\mathrm{N}$ nominal sentence is address with punctuation mark and its position is before topical theme at the same time, they are usually used as interpersonal theme.

Example (7)

王和卿：怎么，别扭就有园子了？

朱宋秀: 是啊, 刚才我也说, 得大家想法子啊。和卿先生, 您在外面活动比汉卿强大多了, 认真地帮帮我们 忙吧。没有别的, 回头至至诚诚地唱几出看家戏, 请您给指教指教。(田汉, 2000, p. 43) 
The apposition of $\mathrm{N}+\mathrm{N}$ nominal sentence “和卿先生,” appears in the form of address with tone marker in the discourse. It takes up the position of starting point, and it is used as theme but not topical theme. Personal pronoun “您” is much closer to the predicate verb and it is the participant of the process. “您” is used as topical theme in this chapter. “和卿先生,” appears before the topical theme “您”, so it is acted as interpersonal theme of the whole clauses group (discourse).

Secondly, $\mathrm{N}+\mathrm{N}$ nominal sentence takes up the position of the rest of starting point, it is used as rheme. Generally speaking, theme is the starting point of the discourse, it is usually the subject of the discourse. Rheme is the rest of the starting point and declares the theme. Theme provides given information, while rheme carries new information. Used as rheme, $\mathrm{N}+\mathrm{N}$ nominal sentence mainly provides new information and helps to construct the information structure of the whole discourse.

Example (8)

他的现在, 母亲的过去。母亲在时间里停留。她还是那样年轻, 就像那个摘花的小姑娘, 像他的妹妹。他可 是老多了, 他的脸上刻了很多岁月。(汪曾祺, 2000, p. 3)

In Example (8), the attributive-center of $\mathrm{N}+\mathrm{N}$ nominal sentence “母亲的过去。”, follows and declares the theme “他的现在”. It is used as rheme in the discourse. Different from Indo-european language, nominal sentence in mandarin Chinese can be used as predicate and rheme alone in the discourse.

Thirdly, $\mathrm{N}+\mathrm{N}$ nominal sentence takes up the position of duality and is used as dual identity--both of theme and rheme. Excepting used as theme and rheme respectively, $\mathrm{N}+\mathrm{N}$ nominal sentence can be used as theme and rheme at the same time. While it has two dual identity in the discourse, it is usually a valid means of discourse cohesion and coherence.

Example (9)

“我也没跟她多说话。那个做男傧相的人，曹元朗的朋友，缠住她一刻不放松，我看他对唐晓芙很有意思。” (钱钟书, 1980, p. 134)

The attributive-center of N+N nominal sentence “曹元朗的朋友,” helps to explain “那个做男傧相的人,”. In the two clauses pair, giving new information is its function, and it is the rheme of “那个做男傧相的人”. At the same time, the two clauses pair combines an integration as an apposition phrase, used as theme for the following clause. That is to say, “曹元朗的朋友,” has dual identity in the whole clauses group. It is the rheme of the preceding part and the theme of the following part. The N+N nominal sentence “曹元朗的朋友,” makes use of its dual identity to connect its preceding part and the following part. By this way, the clauses group incorporate to an integrity, which is the systemic part of the discourse. And it is one of the effective ways to construct a discourse.

\section{Conclusion}

$\mathrm{N}+\mathrm{N}$ nominal sentence is an important structure type of nominal sentence. Attributive-center, combination, apposition and subject-predicate are its main structure types. And these types are easily found in main literary genres. 
By analyzing the language materials from main literary genres, we assert that they have different distribution probability. It shows a certain trend of dominant hierarchy: poem $>$ drama $>$ novel $>$ prose. On its basis, subclass distribution proportion of $\mathrm{N}+\mathrm{N}$ nominal sentence is also considered. The statistical result shows no matter what kind of literary genres, attributive-center structure is the type with maximum quantity, and appositive structure is the type with minimum quantity. The two statistical results indicate that first, most of $\mathrm{N}+\mathrm{N}$ nominal sentence is nominal; second, the choice of sentences pattern is limited by genres.

Different from $\mathrm{N}+\mathrm{N}$ nominal phrase, the function of $\mathrm{N}+\mathrm{N}$ nominal sentence is textual. In the discourse, $\mathrm{N}+\mathrm{N}$ nominal sentence can take up the position of the starting point, and be used as theme; it can also take up the position of the rest, and be used as rheme. Besides that, it can be dual identity, used as theme and rheme at the same time. Used as theme and rheme at the same time, $\mathrm{N}+\mathrm{N}$ nominal sentence not only constructs the information structure to deliver textual information, but also its a vital means of discourse cohesion and coherence.

\section{References}

Chao, Y. R. (2011). A grammar of spoken Chinese. Beijing: The Commercial Press.

Halliday, M. A. K. (1967). Notes on transitivity and theme in English (Part 2), Journal of Linguistics, 3, 177-274.

Halliday, M. A. K. (2008). An introduction to functional grammar. Beijing: Foreign Language Teaching and Research Press.

He, L. (2003). On the pragmatic study of "NP+zai+NpL+Vzhe” and its synonymic pattern. Linguistic Sciences, 2(4), 38-44.

Lv, S. X. (1979). Problems in analyzing Chinese grammar. Beijing: The Commercial Press.

Shao, J. M. (2001). General theory of modern Chinese (pp. 209-212). Shanghai: Shanghai Education Press.

Shen, J. X. (2012). On minor sentences and flowing sentences in Chinese: In commemoration of 120th Birthday of Yuan Ren Chao. Studies of the Chinese Language, 5, 403-415.

Xing, F. Y. (1996). Chinese grammar. Changchun: Northeast Normal University Press.

Xing, F. Y. (2004). A selection of the observation point: Hypothesis of the clause-oriented approach. Chinese Linguistics, 1, 47-51.

$\mathrm{Xu}$, J. J. (2001). Modern Chinese discourse linguistics. Beijing: The Commercial Press.

Zhang, B. J., \& Fang, M. (1994). Thematic structure of spoken Chinese. Journal of Peking University (philosophy and social science edition), 2, 66-75.

钱钟书. (1980). 《围城》. Bejing: People’s Literature Publishing House.

苏雪林. (2013). 《山窗读画记》. Wuhan: Changjiang Literature and Arts Press.

田汉. (2000). 《关汉卿》. Beijing: The Writers Publishing House.

汪曾祺. (2000). 《复仇》 Beijing: China Youth publishing Group.

叶延滨. (1990). 《干妈・她没有自己的名字》. Jinnan: Tomorrow Publishing House. 